\title{
Optimal Biomass Transportation Model
}

\author{
K. M. Chu ${ }^{1}$ and A. Abdulrazik1, $2^{*}$ \\ ${ }^{1}$ Faculty of Chemical and Process Engineering Technology, Universiti Malaysia Pahang, 26300 Pahang, Malaysia. \\ ${ }^{2}$ Centre for Sustainability of Ecosystem and Earth Resources, Universiti Malaysia Pahang, 26300 Pahang, Malaysia.
}

ABSTRACT - The transportation represents a key proportion of the operational cost for the biomass industries worldwide. As biomasses are mainly carried by trucks for parts of the transportation, the focus of this paper is on the transport of treated and untreated biomass (rice husk, empty fruit bunch, and woody biomass) by large, medium and small trucks. The objectives were to formulate biomass transportation model for transporting treated and untreated biomass resources and to obtain optimal result for selecting the best transportation mode. By screening of biomass types, locations for treated and untreated biomass resources and screening of suitable transportation mode used, the important model parameters were obtained and linear programming for minimizing overall transportation costs was formulated. General Algebraic Modelling System (GAMS) software was used to solve the optimization formulations. From the optimization result obtained by using GAMS, large truck was selected to be the best transportation mode for treated, untreated and hybrid biomass since it showed minimal overall transportation cost.
ARTICLE HISTORY

Received: 1 Dec 2020

Revised: 12 April 2021

Accepted: 19 April 2021

\section{KEYWORDS}

Biomass

Transportation Mode

Linear Programming

GAMS

\section{INTRODUCTION}

Biomass is one of the most vital renewables in Malaysia together with solar, small hydro power and biogas resources [1]. Biomass could produce energy in the form of biofuels which have huge potentials to solve the challenges of energy crisis faced by the world nowadays [2]. It differs from fossil resources in many ways, including organic, inorganic, energy contents and physical properties [3]. Malaysia as a major agriculture commodity producer is well-positioned against the ASEAN countries to encourage the utilization of biomass as a renewable energy source in the national energy mix [1,4]. One of the biggest challenges for expanding the bioenergy industry is a sustainable and economical procurement system for biomass feedstock supplies. Transportation is a key factor that often accounts for significant portion of the delivered cost [5]. In the context of biomass, transportation efficiency is a challenge by considering the whole supply chain.

Transportation from forestry harvest areas to mills costs the forestry industry millions of dollars annually, accounting for up to half of the operational costs in forestry supply chains [6]. Given the level of spending on transportation costs, even small increases in efficiency can reduce costs substantially [7]. Biomass transportation cost will dictate feedstock receiving cost and the overall biomass market competitiveness. There are several modes of transportation are used in forestry: truck, train, ship and water [2]. As biomass are mainly delivered by trucks as the transportation mode, the focus is on the transport of treated and untreated biomass by different types of trucks, i.e small, medium and large sizes of trucks. Issues are related to transportation cost minimization target.

Previous biomass transportation models were studied by [8] for biomass collection, storage and plant sizing for ethanol production, and the new integrated biomass logistical centre (IBLC) by [9]. There was another work which studied about the solution of multi-echelon biomass supply chain synthesis problem by proposed an improved mathematical model. The problems which take in consideration by the researchers are processing hub selection, biomass allocation design and transportation mode selection, with the consideration of vehicle capacity constraints [10].

The previous works that were mentioned have not focus on the type of trucks that will be used in hauling the biomass as well as the conditions of the resources. Hence, the objectives of this paper are to formulate optimization model for biomass transportation using treated and untreated biomass resources (rice husk, empty fruit bunch and woody biomass) and to obtain optimal result for selecting the best transportation mode. The important model parameters are obtained to formulate linear programming for minimizing overall transportation cost by selection of suitable biomass resources, identify locations for treated and untreated biomass resources, and screen for suitable transportation modes. The GAMS software is used to solve the optimization formulation and to obtain the best transportation mode to transport treated, untreated and hybrid biomass resources.

\section{METHODOLOGY}

There were three scenarios were studied in this paper; (1) Optimization model for biomass transportation using treated biomass resources, (2) Optimization model for biomass transportation using untreated biomass resources and (3) Optimization model for biomass transportation using hybrid biomass resources (treated and untreated). The overall 
transportation costs considered in both cases are the raw material cost, transportation cost and carbon dioxide $\left(\mathrm{CO}_{2}\right)$ emission cost. Parameters that used in the modelling were obtained from sources include Google Maps for distance determinations, from [3], and [11]. It is need to mentione that, there will be a significant difference on the raw material cost between treated and untreated ones since is the former is expensive compared to the latter. Figure 1 shows the flow chart of the whole research process for all scenarios. . First, three suitable and commonly used biomass resources available in Malaysia were chosen according to their availabilities The locations for treated and untreated biomass resources were identified based on surveys and communications Then, suitable modes of transportation that include all categories of trucks were screened. Next, model parameters which are crucial obtained are used to formulate linear programming for minimizing overall transport cost.

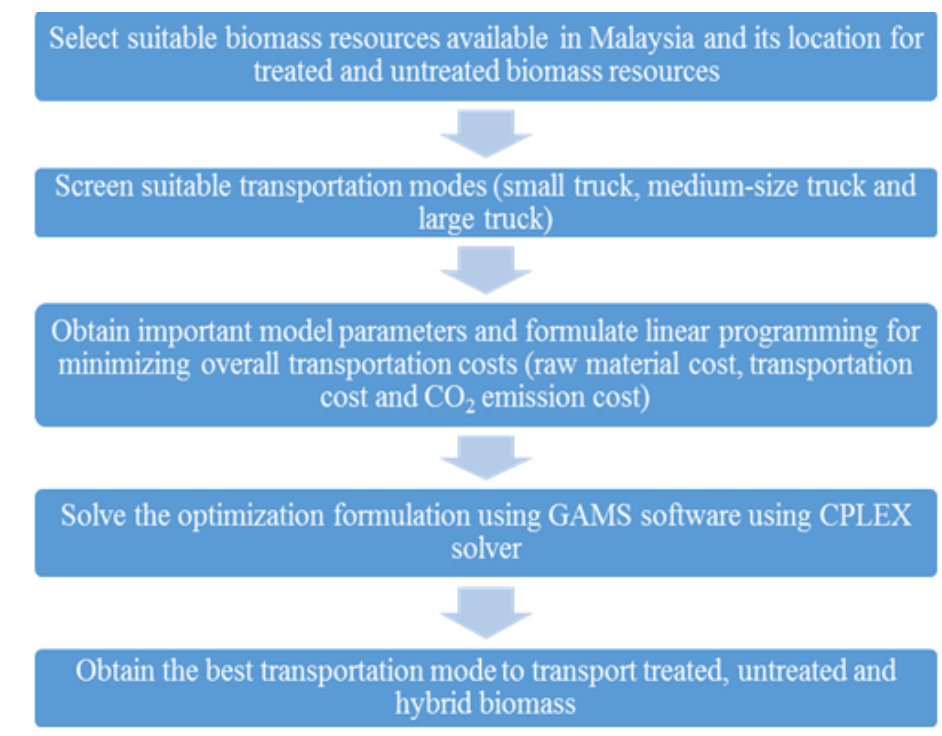

Figure 1. Flow chart of methodology

The formulation for the optimal selection was based on the overall transportation costs of treated and untreated biomass in month basis. The raw material cost, transportation cost and $\mathrm{CO}_{2}$ emission cost of each truck type had been considered, while the other associated costs were neglected. Three scenarios are simulated: Optimization model for biomass transportation using (1) all treated biomass resources, (2) all untreated biomass resources and (3) hybrid - random mixed of treated and untreated biomass resources. For the formulation each scenario, details as shown below;

\section{Scenario 1: Optimization model for biomass transportation using all treated biomass resources}

In the model's formulation for Scenario 1, overall transportation cost minimization for treated biomass resources was the objective function. It was indicated by considering raw material cost of treated biomass resources, transportation cost for treated biomass resources and carbon dioxide gas emission cost of truck. Mathematical model that contain the objective function's details are shown by Eq. (1) till Eq. (4). Meanwhile, Eq. (5) till Eq. (7) represent the model's constraints. Explanations for each formulation for Scenario 1 were tabulated in Table 1. Following the table, each term in all of those formulations was explained in Table 2.

$$
\begin{array}{cr}
O T C_{x}=R M C_{x}+T C_{x}+C O 2 E C_{x} & \text { Eq. (1) } \\
R M C_{x}=[(x 1+x 2+x 3) * C T R H T]+[(x 4+x 5+x 6) * C T E F B T]+[(x 7+x 8+x 9) * C T W B T] & \text { Eq. (2) } \\
T C_{x}=\{[(F R E Q S * x 1+F R E Q M * x 2+F R E Q L * x 3) * D I S T T R H]+[(F R E Q S * x 4+F R E Q M * x 5+F R E Q L * \\
x 6) * D I S T T E F B]+[(F R E Q S * x 7+F R E Q M * x 8+F R E Q L * x 9) * D I S T T W B]\} * T C T K & \text { Eq. (3) } \\
C O 2 E C_{x}=\{[(D I S T T R H * x 1+D I S T T E F B * x 4+D I S T T W B * x 7) * L C S * F R E Q S]+[(D I S T T R H * x 2+ \\
\operatorname{DISTTEFB} * x 5+D I S T T W B * x 8) * L C M * F R E Q M]+[(D I S T T R H * x 3+D I S T T E F B * x 6+D I S T T W B * x 9) * \\
L C L * F R E Q L]\} * C O 2 T K * C C O 2 T & \text { Eq. (4) } \\
\mathrm{x} 1+\mathrm{x} 2+\mathrm{x} 3=\mathrm{e}=\mathrm{SATRH} & \text { Eq. (5) } \\
\mathrm{x} 4+\mathrm{x} 5+\mathrm{x} 6=\mathrm{e}=\text { SATEFB } & \text { Eq. (6) } \\
\mathrm{x} 7+\mathrm{x} 8+\mathrm{x} 9=\mathrm{e}=\text { SATWB } & \text { Eq. (7) }
\end{array}
$$


Table 1. Description of mathematical formulations in Scenario 1

\begin{tabular}{|c|l|}
\hline Formulation & \multicolumn{1}{c|}{ Description } \\
\hline Eq. (1) & Objective function and overall transportation cost equation for treated biomass in RM/month \\
\hline Eq. (2) & Raw material cost for treated biomass in RM/month \\
\hline Eq. (3) & Transportation cost for treated biomass in RM/month \\
\hline Eq. (4) & Carbon dioxide gas emission cost for delivering treated biomass in RM/month \\
\hline Eq. (5) & $\begin{array}{l}\text { Constraint to ensure the supply ability of supplier for treated rice husk can cover the amount of raw } \\
\text { material needed in plant }\end{array}$ \\
\hline Eq. (6) & $\begin{array}{l}\text { Constraint to ensure the supply ability of supplier for treated empty fruit bunch can cover the amount } \\
\text { of raw material needed in plant }\end{array}$ \\
\hline Eq. (7) & $\begin{array}{l}\text { Constraint to ensure the supply ability of supplier for treated woody biomass can cover the amount of } \\
\text { raw material needed in plant }\end{array}$ \\
\hline
\end{tabular}

Table 2. Description of terms used in Eq. (1) till Eq. (7)

\begin{tabular}{|c|c|c|}
\hline Term & Category & Description \\
\hline$O T C_{x}$ & Parameter & Overall transportation cost of treated biomass in $\mathrm{RM} / \mathrm{month}$ \\
\hline$R M C_{x}$ & Parameter & $\begin{array}{l}\text { Overall transportation cost factor for raw material cost of treated biomass in } \\
\mathrm{RM} / \text { month }\end{array}$ \\
\hline$T C_{x}$ & Parameter & $\begin{array}{l}\text { Overall transportation cost factor for transportation cost of treated biomass in } \\
\mathrm{RM} / \text { month }\end{array}$ \\
\hline$C O 2 E C_{x}$ & Parameter & $\begin{array}{l}\text { Overall transportation cost factor for carbon dioxide gas emission cost of treated } \\
\text { biomass in } \mathrm{RM} / \text { month }\end{array}$ \\
\hline CTRHT & Parameter & Cost of treated rice husk per tonne in RM/tons \\
\hline CTEFBT & Parameter & Cost of treated empty fruit bunch per tonne in RM/tons \\
\hline CTWBT & Parameter & Cost of treated woody biomass per tonne in RM/tons \\
\hline FREQS & Parameter & Frequency of small truck for deliver biomass from supplier to plant \\
\hline FREQM & Parameter & Frequency of medium truck for deliver biomass from supplier to plant \\
\hline$F R E Q L$ & Parameter & Frequency of large truck for deliver biomass from supplier to plant \\
\hline DISTTRH & Parameter & Distance to deliver treated rice husk from the supplier to plant per trip in $\mathrm{m}$ \\
\hline DISTTEFB & Parameter & Distance to deliver treated empty fruit bunch from the supplier to plant per trip in $\mathrm{m}$ \\
\hline DISTTWB & Parameter & Distance to deliver treated woody biomass from the supplier to plant per trip in $\mathrm{m}$ \\
\hline TCTK & Parameter & Average transportation cost of truck per tonne per kilometre in RM/tons.km \\
\hline$L C S$ & Parameter & Loading capacity of small truck in tons \\
\hline$L C M$ & Parameter & Loading capacity of medium truck in tons \\
\hline$L C L$ & Parameter & Loading capacity of large truck in tons \\
\hline CO2TK & Parameter & Carbon dioxide gas emitted by truck per tonne per kilometre \\
\hline CCO2T & Parameter & Emission cost of carbon dioxide per tonne in RM/ tons \\
\hline SATRH & Parameter & Supply ability of supplier for treated rice husk \\
\hline SATEFB & Parameter & Supply ability of supplier for treated empty fruit bunch \\
\hline SATWB & Parameter & Supply ability of supplier for treated woody biomass \\
\hline$x 1$ & $\begin{array}{l}\text { Decision } \\
\text { Variable }\end{array}$ & Amount of treated rice husk transported by small truck a month in tons/month \\
\hline$x 2$ & $\begin{array}{l}\text { Decision } \\
\text { Variable }\end{array}$ & Amount of treated rice husk transported by medium truck a month in tons/month \\
\hline$x 3$ & $\begin{array}{l}\text { Decision } \\
\text { Variable }\end{array}$ & Amount of treated rice husk transported by large truck a month in tons/month \\
\hline$x 4$ & $\begin{array}{l}\text { Decision } \\
\text { Variable }\end{array}$ & $\begin{array}{l}\text { Amount of treated empty fruit bunch transported by small truck a month in } \\
\text { tons/month }\end{array}$ \\
\hline$x 5$ & $\begin{array}{l}\text { Decision } \\
\text { Variable }\end{array}$ & $\begin{array}{l}\text { Amount of treated empty fruit bunch transported by medium truck a month in } \\
\text { tons/month }\end{array}$ \\
\hline$x 6$ & $\begin{array}{l}\text { Decision } \\
\text { Variable }\end{array}$ & $\begin{array}{l}\text { Amount of treated empty fruit bunch transported by large truck a month in } \\
\text { tons/month }\end{array}$ \\
\hline$x 7$ & $\begin{array}{l}\text { Decision } \\
\text { Variable }\end{array}$ & Amount of treated woody biomass transported by small truck a month in tons/month \\
\hline$x 8$ & $\begin{array}{l}\text { Decision } \\
\text { Variable }\end{array}$ & $\begin{array}{l}\text { Amount of treated woody biomass transported by medium truck a month in } \\
\text { tons/month }\end{array}$ \\
\hline$x 9$ & $\begin{array}{l}\text { Decision } \\
\text { Variable }\end{array}$ & Amount of treated woody biomass transported by large truck a month in tons/month \\
\hline
\end{tabular}




\section{Scenario 2: Optimization model for biomass transportation using all untreated biomass resources}

In the model's formulation for Scenario 2, overall transportation cost minimization for untreated biomass resources was the objective function. It was indicated by considering raw material cost of untreated biomass resources, transportation cost for untreated biomass resources and carbon dioxide gas emission cost of truck. Linear programming that contain the objective function's details are shown by Eq. (8) till Eq. (11). Meanwhile, Eq. (12) till Eq. (15) represent the model's constraints. Explanations for each formulation for Scenario 2 were tabulated in Table 3. Following the table, each term in all of those formulations was explained in Table 4.

$$
O T C_{y}=R M C_{y}+T C_{y}+C O 2 E C_{y}
$$

$$
\begin{aligned}
& R M C_{y}=[(y 1+y 2+y 3) * C U R H T]+[(y 4+y 5+y 6) * C U E F B T]+[(y 7+y 8+y 9) * C U W B T] \text { Eq. (9) } \\
T C_{y}= & \{[(F R E Q S * y 1+F R E Q M * y 2+F R E Q L * y 3) * D I S T U R H]+[(F R E Q S * y 4+F R E Q M * y 5+F R E Q L * \\
y 6) * D I S T U E F B]+[(F R E Q S * y 7+F R E Q M * y 8+F R E Q L * y 9) * D I S T U W B]\} * T C T K & \text { Eq. }(10)
\end{aligned}
$$

${\text { CO } 2 E C_{y}=\{[(D I S T U R H}^{*} y 1+$ DISTUEFB $* y 4+$ DISTUWB $\left.\left.* y 7\right) * L C S * F R E Q S\right]+[(D I S T U R H * y 2+$ DISTUEFB * y5 + DISTUWB *y8) *LCM * FREQM $]+[($ DISTURH *y3 + DISTUEFB *y6 + DISTUWB * y9) * $L C L * F R E Q L]\} * C O 2 T K * C C O 2 T$

$$
\begin{aligned}
& \mathrm{y} 1+\mathrm{y} 2+\mathrm{y} 3=\mathrm{e}=\text { SAURH } \\
& \mathrm{y} 4+\mathrm{y} 5+\mathrm{y} 6=\mathrm{e}=\text { SAUEFB } \\
& \mathrm{y} 7+\mathrm{y} 8+\mathrm{y} 9=\mathrm{e}=\text { SAUWB }
\end{aligned}
$$

Table 3. Description of mathematical formulations in Scenario 2

\begin{tabular}{|c|l|}
\hline Formulation & \multicolumn{1}{c|}{ Description } \\
\hline Eq. (8) & Objective function and overall transportation cost equation for untreated biomass in RM/month \\
\hline Eq. (9) & Raw material cost for untreated biomass in RM/month \\
\hline Eq. (10) & Transportation cost for untreated biomass in RM/month \\
\hline Eq. (11) & Carbon dioxide gas emission cost for deliver untreated biomass in RM/month \\
\hline Eq. (12) & $\begin{array}{l}\text { Constraint to ensure the supply ability of supplier for untreated rice husk can cover the amount of raw } \\
\text { material needed in plant }\end{array}$ \\
\hline Eq. (13) & $\begin{array}{l}\text { Constraint to ensure the supply ability of supplier for untreated empty fruit bunch can cover the amount } \\
\text { of raw material needed in plant }\end{array}$ \\
\hline Eq. (14) & $\begin{array}{l}\text { Constraint to ensure the supply ability of supplier for untreated woody biomass can cover the amount } \\
\text { of raw material needed in plant }\end{array}$ \\
\hline
\end{tabular}

Table 4. Description of terms used in Eq. (8) till Eq. (14)

\begin{tabular}{|c|c|c|c|}
\hline Term & Category & Description \\
\hline$O T C_{y}$ & Parameter & Overall transportation cost of untreated biomass in RM/month \\
\hline$R M C_{y}$ & Parameter & Overall transportation cost factor for raw material cost of untreated biomass in RM/month \\
\hline$T C_{y}$ & Parameter & $\begin{array}{c}\text { Overall transportation cost factor for transportation cost of untreated biomass in } \\
\mathrm{RM} / \text { month }\end{array}$ \\
\hline$C O 2 E C_{y}$ & Parameter & $\begin{array}{c}\text { Overall transportation cost factor for carbon dioxide gas emission cost of untreated } \\
\text { biomass in RM/month }\end{array}$ \\
\hline$C U R H T$ & Parameter & Cost of untreated rice husk per tonne in RM/tons \\
\hline$C U E F B T$ & Parameter & Cost of untreated empty fruit bunch per tonne in RM/tons \\
\hline$C U W B T$ & Parameter & Cost of untreated woody biomass per tonne in RM/tons \\
\hline$F R E Q S$ & Parameter & Frequency of small truck for deliver biomass from supplier to plant \\
\hline$F R E Q M$ & Parameter & Frequency of medium truck for deliver biomass from supplier to plant \\
\hline$F R E Q L$ & Parameter & Frequency of large truck for deliver biomass from supplier to plant \\
\hline$D I S T U R H$ & Parameter & Distance to deliver untreated rice husk from the supplier to plant per trip in $\mathrm{m}$ \\
\hline$D I S T U E F B$ & Parameter & Distance to deliver untreated empty fruit bunch from the supplier to plant per trip in $\mathrm{m}$ \\
\hline$D I S T U W B$ & Parameter & Distance to deliver untreated woody biomass from the supplier to plant per trip in $\mathrm{m}$ \\
\hline$T C T K$ & Parameter & Average transportation cost of truck per tonne per kilometre in RM/tons.km \\
\hline$L C S$ & Parameter & Loading capacity of small truck in tons \\
\hline$L C M$ & Parameter & Loading capacity of medium truck in tons \\
\hline$L C L$ & Parameter & Loading capacity of large truck in tons \\
\hline
\end{tabular}




\begin{tabular}{|c|c|c|}
\hline CO2TK & Parameter & Carbon dioxide gas emitted by truck per tonne per kilometre \\
\hline CCO2T & Parameter & Emission cost of carbon dioxide per tonne in RM/ tons \\
\hline SAURH & Parameter & Supply ability of supplier for untreated rice husk \\
\hline SAUEFB & Parameter & Supply ability of supplier for untreated empty fruit bunch \\
\hline SAUWB & Parameter & Supply ability of supplier for untreated woody biomass \\
\hline$y 1$ & $\begin{array}{l}\text { Decision } \\
\text { Variable }\end{array}$ & Amount of untreated rice husk transported by small truck a month in tons/month \\
\hline$y 2$ & $\begin{array}{l}\text { Decision } \\
\text { Variable }\end{array}$ & Amount of untreated rice husk transported by medium truck a month in tons/month \\
\hline$y 3$ & $\begin{array}{l}\text { Decision } \\
\text { Variable }\end{array}$ & Amount of untreated rice husk transported by large truck a month in tons/month \\
\hline$y 4$ & $\begin{array}{l}\text { Decision } \\
\text { Variable }\end{array}$ & Amount of untreated empty fruit bunch transported by small truck a month in tons/month \\
\hline$y 5$ & $\begin{array}{l}\text { Decision } \\
\text { Variable }\end{array}$ & $\begin{array}{l}\text { Amount of untreated empty fruit bunch transported by medium truck a month in } \\
\text { tons/month }\end{array}$ \\
\hline$y 6$ & $\begin{array}{l}\text { Decision } \\
\text { Variable }\end{array}$ & Amount of untreated empty fruit bunch transported by large truck a month in tons/month \\
\hline$y 7$ & $\begin{array}{l}\text { Decision } \\
\text { Variable }\end{array}$ & Amount of untreated woody biomass transported by small truck a month in tons/month \\
\hline$y 8$ & $\begin{array}{l}\text { Decision } \\
\text { Variable }\end{array}$ & Amount of untreated woody biomass transported by medium truck a month in tons/month \\
\hline$y 9$ & $\begin{array}{l}\text { Decision } \\
\text { Variable }\end{array}$ & Amount of untreated woody biomass transported by large truck a month in tons/month \\
\hline
\end{tabular}

\section{Scenario 3: Optimization model for biomass transportation using hybrid-random mixed of treated and untreated biomass resources}

Scenario 3 is a scenario when biomass transported is neither all treated biomass nor untreated biomass. In other word, it is the scenario when some of the biomass delivered is treated while some are untreated. In this scenario, we had made an assumption that rice husk and empty fruit bunch used is treated while the woody biomass used is untreated. In the model's formulation for Scenario 3, overall transportation cost minimization for hybrid biomass resources was the objective function. It was indicated by considering raw material cost of hybrid biomass resources, transportation cost for treated biomass resources and carbon dioxide gas emission cost of truck. Modelling that contain the objective function's details are shown by Eq. (15) till Eq. (18). Meanwhile, Eq. (19) till Eq. (21) represent the model's constraints. Explanations for each formulation for Scenario 3 were tabulated in Table 5. Following the table, each term in all of those formulations was explained in Table 6.

$$
\begin{aligned}
& O T C_{z}=R M C_{z}+T C_{z}+C O 2 E C_{z} \\
& R M C_{z}=[(z 1+z 2+z 3) * C T R H T]+[(z 4+z 5+z 6) * C T E F B T]+[(z 7+z 8+z 9) * C U W B T] \\
& T C_{z}=\{[(F R E Q S * z 1+F R E Q M * z 2+F R E Q L * z 3) * D I S T T R H]+[(F R E Q S * z 4+F R E Q M * z 5+F R E Q L * \\
& z 6) * D I S T T E F B]+[(F R E Q S * z 7+F R E Q M * z 8+F R E Q L * z 9) * D I S T U W B]\} * T C T K \\
& \text { CO2EC }_{z}=\{[(D I S T T R H * z 1+\text { DISTTEFB } * z 4+\text { DISTUWB } * z 7) * L C S * F R E Q S]+[(D I S T T R H * z 2+ \\
& \text { DISTTEFB } * z 5+\text { DISTUWB } * z 8) * L C M * F R E Q M]+[(D I S T T R H * z 3+\text { DISTTEFB } * z 6+\text { DISTUWB } * z 9) * \\
& L C L * F R E Q L]\} * C O 2 T K * C C O 2 T \\
& \mathrm{z} 1+\mathrm{z} 2+\mathrm{z} 3=\mathrm{e}=\mathrm{SATRH} \\
& \mathrm{z} 4+\mathrm{z} 5+\mathrm{z} 6=\mathrm{e}=\text { SATEFB } \\
& \mathrm{z} 7+\mathrm{z8}+\mathrm{z} 9=\mathrm{e}=\mathrm{SAUWB}
\end{aligned}
$$


Table 5. Description of mathematical formulations in Scenario 3

\begin{tabular}{|c|l|}
\hline Formulation & \multicolumn{1}{c|}{ Description } \\
\hline Eq. (15) & Objective function and overall transportation cost equation for hybrid biomass in RM/month \\
\hline Eq. (16) & Raw material cost for hybrid biomass in RM/month \\
\hline Eq. (17) & Transportation cost for hybrid biomass in RM/month \\
\hline Eq. (18) & Carbon dioxide gas emission cost for deliver hybrid biomass in RM/month \\
\hline Eq. (19) & $\begin{array}{l}\text { Constraint to ensure the supply ability of supplier for hybrid-treated rice husk can cover the amount of } \\
\text { raw material needed in plant }\end{array}$ \\
\hline Eq. (20) & $\begin{array}{l}\text { Constraint to ensure the supply ability of supplier for hybrid-treated empty fruit bunch can cover the } \\
\text { amount of raw material needed in plant }\end{array}$ \\
\hline Eq. (21) & $\begin{array}{l}\text { Constraint to ensure the supply ability of supplier for hybrid-untreated woody biomass can cover the } \\
\text { amount of raw material needed in plant }\end{array}$ \\
\hline
\end{tabular}

Table 6. Description of terms used in Eq. (15) till Eq. (21)

\begin{tabular}{|c|c|c|}
\hline Term & Category & Description \\
\hline$O T C_{z}$ & Parameter & Overall transportation cost of hybrid biomass in $\mathrm{RM} / \mathrm{month}$ \\
\hline$R M C_{z}$ & Parameter & $\begin{array}{l}\text { Overall transportation cost factor for raw material cost of hybrid biomass in } \\
\mathrm{RM} / \mathrm{month}\end{array}$ \\
\hline$T C_{z}$ & Parameter & $\begin{array}{l}\text { Overall transportation cost factor for transportation cost of hybrid biomass in } \\
\mathrm{RM} / \text { month }\end{array}$ \\
\hline $\mathrm{CO} E C_{z}$ & Parameter & $\begin{array}{l}\text { Overall transportation cost factor for carbon dioxide gas emission cost of hybrid } \\
\text { biomass in RM/month }\end{array}$ \\
\hline CTRHT & Parameter & Cost of treated rice husk per tonne in RM/tons \\
\hline CTEFBT & Parameter & Cost of treated empty fruit bunch per tonne in RM/tons \\
\hline CUWBT & Parameter & Cost of untreated woody biomass per tonne in RM/tons \\
\hline FREQS & Parameter & Frequency of small truck for deliver biomass from supplier to plant \\
\hline FREQM & Parameter & Frequency of medium truck for deliver biomass from supplier to plant \\
\hline$F R E Q L$ & Parameter & Frequency of large truck for deliver biomass from supplier to plant \\
\hline DISTTRH & Parameter & Distance to deliver treated rice husk from the supplier to plant per trip in $\mathrm{m}$ \\
\hline DISTTEFB & Parameter & $\begin{array}{l}\text { Distance to deliver treated empty fruit bunch from the supplier to plant per trip in } \\
\mathrm{m}\end{array}$ \\
\hline DISTUWB & Parameter & $\begin{array}{l}\text { Distance to deliver untreated woody biomass from the supplier to plant per trip } \\
\text { in } \mathrm{m}\end{array}$ \\
\hline TCTK & Parameter & Average transportation cost of truck per tonne per kilometre in RM/tons.km \\
\hline LCS & Parameter & Loading capacity of small truck in tons \\
\hline$L C M$ & Parameter & Loading capacity of medium truck in tons \\
\hline$L C L$ & Parameter & Loading capacity of large truck in tons \\
\hline CO2TK & Parameter & Carbon dioxide gas emitted by truck per tonne per kilometre \\
\hline CCO2T & Parameter & Emission cost of carbon dioxide per tonne in RM/ tons \\
\hline SATRH & Parameter & Supply ability of supplier for treated rice husk \\
\hline SATEFB & Parameter & Supply ability of supplier for treated empty fruit bunch \\
\hline SAUWB & Parameter & Supply ability of supplier for untreated woody biomass \\
\hline$z 1$ & $\begin{array}{l}\text { Decision } \\
\text { Variable }\end{array}$ & Amount of treated rice husk transported by small truck a month in tons/month \\
\hline$z 2$ & $\begin{array}{l}\text { Decision } \\
\text { Variable }\end{array}$ & Amount of treated rice husk transported by medium truck a month in tons/month \\
\hline$z 3$ & $\begin{array}{l}\text { Decision } \\
\text { Variable }\end{array}$ & Amount of treated rice husk transported by large truck a month in tons/month \\
\hline$z 4$ & $\begin{array}{l}\text { Decision } \\
\text { Variable }\end{array}$ & $\begin{array}{l}\text { Amount of treated empty fruit bunch transported by small truck a month in } \\
\text { tons/month }\end{array}$ \\
\hline$z 5$ & $\begin{array}{l}\text { Decision } \\
\text { Variable }\end{array}$ & $\begin{array}{l}\text { Amount of treated empty fruit bunch transported by medium truck a month in } \\
\text { tons/month }\end{array}$ \\
\hline$z 6$ & $\begin{array}{l}\text { Decision } \\
\text { Variable }\end{array}$ & $\begin{array}{l}\text { Amount of treated empty fruit bunch transported by large truck a month in } \\
\text { tons/month }\end{array}$ \\
\hline$z 7$ & $\begin{array}{l}\text { Decision } \\
\text { Variable }\end{array}$ & $\begin{array}{l}\text { Amount of untreated woody biomass transported by small truck a month in } \\
\text { tons/month }\end{array}$ \\
\hline$z 8$ & $\begin{array}{l}\text { Decision } \\
\text { Variable }\end{array}$ & $\begin{array}{l}\text { Amount of untreated woody biomass transported by medium truck a month in } \\
\text { tons/month }\end{array}$ \\
\hline$z 9$ & $\begin{array}{l}\text { Decision } \\
\text { Variable }\end{array}$ & $\begin{array}{l}\text { Amount of untreated woody biomass transported by large truck a month in } \\
\text { tons/month }\end{array}$ \\
\hline
\end{tabular}




\section{RESULTS AND DISCUSSION}

Figure 2 shows the modelling and formulation for optimal feedstock and transportation selection for (a) all treated biomass, (b) all untreated biomass and (c) hybrid - random mixed of treated and untreated biomass. Meanwhile, Table 7 , Table 8 and Table 9 shows the result for GAMS for optimal feedstock and transportation selection for all treated biomass, all untreated biomass and hybrid - random mixed of treated and untreated biomass respectively.

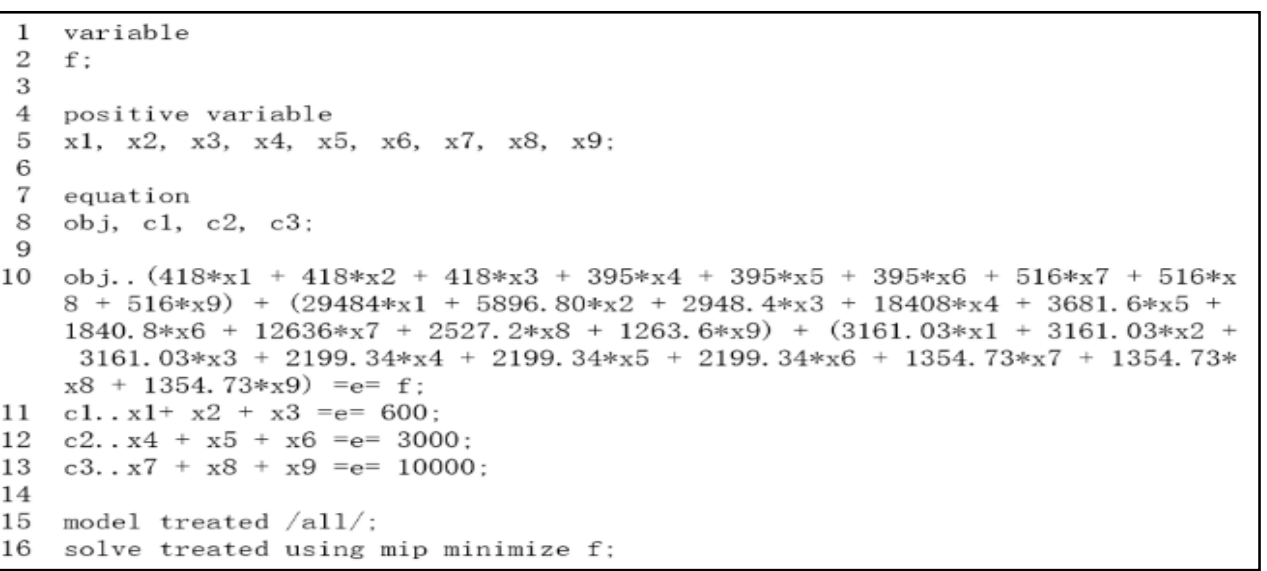

(a)

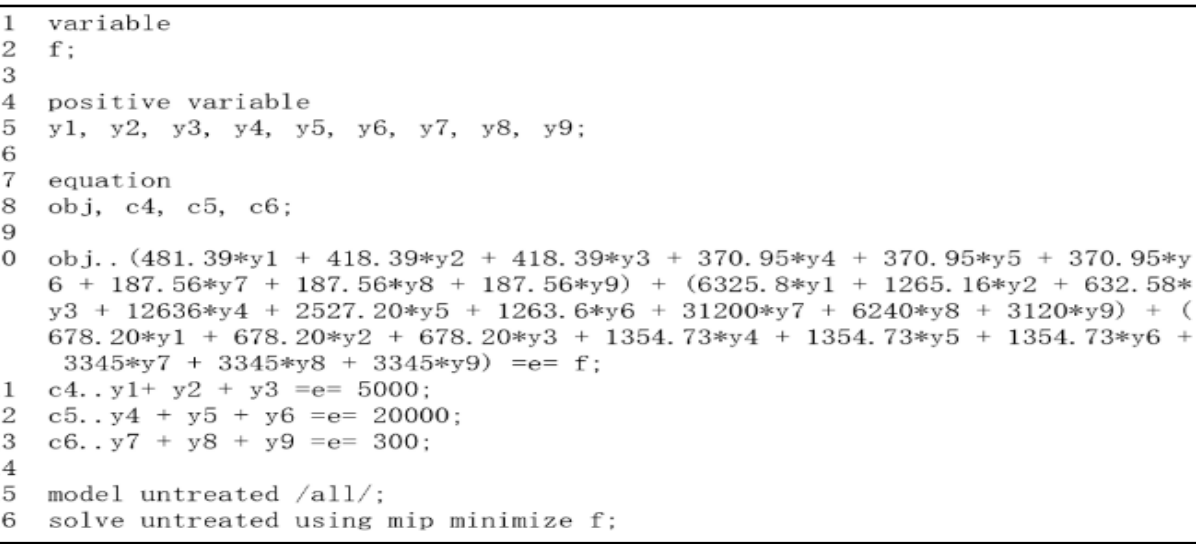

(b)

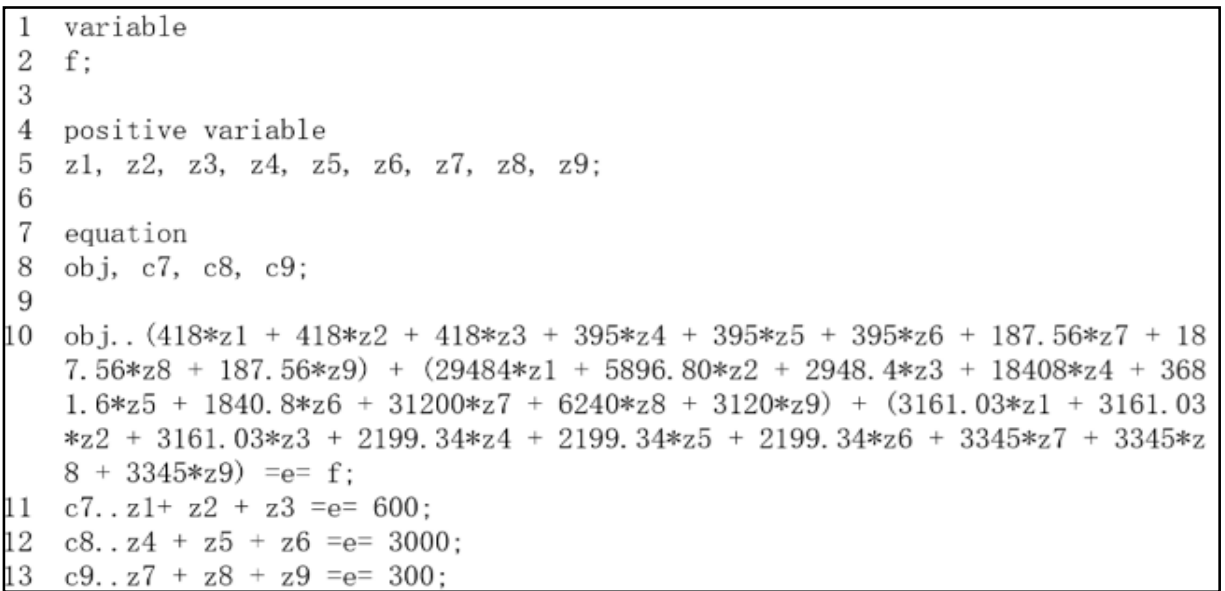

(c)

Figure 2. Modelling and formulation for optimal feedstock and transportation selection for (a) All treated biomass, (b) All untreated biomass and (c) Hybrid - random mixed of treated and untreated biomass. 
Table 7. Result of GAMS for optimal feedstock and transportation selection for all treated biomass

\begin{tabular}{|c|c|}
\hline Decision Variable & Value \\
\hline VAR $\mathrm{f}$ & $4.8565 \mathrm{E}+7$ \\
\hline VAR 1 &. \\
\hline VAR $\times 2$ &. \\
\hline VAR $\times 3$ & 600.000 \\
\hline VAR $\times 4$ &. \\
\hline VAR $\times 5$ &. \\
\hline VAR $\times 6$ & 3000.000 \\
\hline VAR $\times 7$ &. \\
\hline VAR $\times 8$ &. \\
\hline VAR $\times 9$ & 10000.000 \\
\hline
\end{tabular}

Table 8. Result of GAMS for optimal feedstock and transportation selection for all untreated biomass

\begin{tabular}{|c|c|}
\hline Decision Variable & Value \\
\hline VAR f & $7.0427 \mathrm{E}+7$ \\
\hline VAR y1 &. \\
\hline VAR y2 & . \\
\hline VAR y3 & 5000.000 \\
\hline VAR y4 &. \\
\hline VAR y5 & . \\
\hline VAR y6 &. \\
\hline VAR y7 &. \\
\hline VAR y8 & 300000000 \\
\hline VAR y9 & \\
\hline
\end{tabular}

Table 9. Result of GAMS for optimal feedstock and transportation selection for hybrid-random mixed of treated and untreated biomass

\begin{tabular}{|c|c|}
\hline Decision Variable & Value \\
\hline VAR f & $1.9218 \mathrm{E}+7$ \\
\hline VAR z1 &. \\
\hline VAR z2 & . \\
\hline VAR z3 & 600.000 \\
\hline VAR z4 &. \\
\hline VAR z5 &. \\
\hline VAR z6 & 3000.000 \\
\hline VAR z7 &. \\
\hline VAR z8 & . \\
\hline VAR z9 & \\
\hline
\end{tabular}

From the GAMS optimization results and by using CPLEX solver, decision variables and optimal mode of transportation that minimize the objective function were obtained. . From Table 7, Table 8 and Table 9, large truck was the optimal mode of transportation to transport biomass resources for all scenarios (treated, untreated and hybrid). These can be seen based on the values shown by GAMS i.e x3, x6, x9, y3, y6, y9z3, z6 and z9. These values would minimize the overall transportation costs for each scenario of $f$ values, shown in Table 7 to Table 9.

Based on a study about transport and supply logistics of biomass fuels, these results can be explained from fundamental principle based on economy of scale. Generally, the larger the vehicle size, the larger the quantity of biomass being carried, thus the lower the cost per tonne of moving a load. Larger truck has much bigger carting capacities compared to the small truck. In three scenarios above, large truck can carry up to 20 tonnes of biomass resources for one trip compared with the small truck and medium truck which can carry 2 tonnes and 10 tonnes per trip. When the unit costs of transport are considered, the larger truck have lower terminal and trip costs per tonne transported [12].

However, the application of large truck is limited due to physical constraints such as road surface quality. Hence, further study should be continued with a more detailed consideration.

\section{CONCLUSION}

In conclusion, the best simulation model should be selected by the simulation that has the minimal overall transportation cost and the model which fulfil the constraints associated. An optimization model had been formulated for biomass transportation in this research. By using General Algebraic Modelling System (GAMS), the best transportation mode can be selected by using optimal result obtained. From the optimization result with GAMS, it showed that large 
truck is the transportation mode which can give minimal cost consumption in the perspectives of raw material cost, transportation cost and carbon dioxide emission cost for treated, untreated and hybrid biomass. This optimization model can be possibly implemented in any projects to select the best transportation mode used to deliver biomass.

\section{ACKNOWLEDGEMENT}

We would like to thank Faculty of Chemical and Process Engineering Technology, Universiti Malaysia Pahang for the technical assistances and supports in this work.

\section{REFERENCES}

[1] S. F. Salleh, M. E. M. Roslan, A. A. Rahman, A. H. Shamsuddin, T. A. R. T. Abdullah, and B. K. Sovacool, "Transitioning to a sustainable development framework for bioenergy in Malaysia: policy suggestions to catalyse the utilisation of palm oil mill residues," Energy, Sustainability and Society vol. 10, no. 38, 2020, doi: 10.1186/s13705-020-00269-y.

[2] S. Nanda, J.A. Kozinski, and A.K. Dalai, "Lignocellulosic biomass: A review of conversion technologies and fuel products," Current Biochemical Engineering, vol. 3, no. 1, pp. 24-36, 2016, doi: 10.2174/2213385203666150219232000.

[3] T.G. Chuah, A.W. Azlina, Y. Robiah, and R. Omar, "Biomass as the renewable energy sources in Malaysia: an overview," International Journal of Green Energy, vol. 3, no. 3, pp. 323-346, 2006, doi: 10.1080/01971520600704779.

[4] A. Shamsuddin, "Development of renewable energy in Malaysia strategic initiatives for carbon reduction in the power generartion sector," Procedia Engineering, pp. 384-391, 2012, doi: 10.1016/j.proeng.2012.10.150.

[5] N.Z. Atashbar, N. Labadie, and C. Prins, "Modeling and optimization of biomass supply chains: a review and a critical look," IFAC-PapersOnLine, vol. 49, no. 12, pp. 604-615, 2016, doi: 10.1016/j.ifacol.2016.07.742.

[6] T. McDonald, S. Taylor, and J. Valenzuela, "Potential for shared log transport services". 24th Annual COFE Meeting, pp. 115-120, Snowshoe, USA: Corvallis: Council on Forest Engineering, 2001.

[7] M, Palmgren, M. Rönnqvist, and P. Varbrand, "A near exact method for solving the log-truck scheduling problem. International Transactions of Operations Research, pp. 447-464, 2004, doi: 10.1111/j.1475-3995.2004.00469.x.

[8] J. Leboreiro and A. Hilaly, "Biomass transportation model and optimum plant size for the production of ethanol," Bioresoure Technology, vol. 102, no. 3, pp. 2712-23, 2010, doi: 10.1016/j.biortech.2010.10.144.

[9] X. Guo, J. Voogt, B. Annevelink, J.Snels and A. Kanellopoulos, "Optimizing resource utilization in biomass supply chain by creating IBLC," Energies vol. 13, no.22, pp. 6153, 2020, doi: 10.3390/en13226153.

[10] B.S. How, K.Y. Tan, and H. L. Lam, "Transportation decision tool for optimisation of integrated biomass flow with vehicle capacity constraints," Journal of Cleaner Production, vo. 126, pp. 197-223, 2016, doi: 10.1016/j.jclepro.2016.05.142.

[11] F. Perotta, T. Parry, L. C. Neves, T. B., Benbow, and H. Viner, "Comparison of truck fuel consumption measurements with results of existing models and implications for road pavement LCA" Comparison-of-truck-fuel-consumption-measurementsPerrotta-Parry/46aec8924b452c419c04ca51e24db530827162bc, 1970.

[12] J. Allen, M. Browne, H. Palmer, A. Hunter, and J. Boyd, "Transport and supply logistics of biomass fuels," Supply chain options for biomass fuels, 1996. 